\title{
Towards a Classification of Fourth Party Logistics (4PL)
}

\author{
Laurence Saglietto \\ GREDEG UMR CNRS 7321, University of Nice Sophia Antipolis, 0600 Nice, France \\ *Corresponding Author:Laurence.saglietto@gredeg.cnrs.fr
}

Copyright $(0) 2013$ Horizon Research Publishing All rights reserved.

\begin{abstract}
Over just a few years, the outsourcing of logistic functions to various types of logistics services providers (LSPs) has become central to the organization of companies and markets. In this connection, both theorists and practitioners usually present LSPs in terms of classifications, describing their development with the help of representative statistics. However, one may reasonably wonder about the origin of these classifications and the credibility of the statistics, since LSP are not clearly identified in the nomenclatures of economic activities. Then, how to characterize the fourth party logistics (4PL) community? Our aim is to propose a complete analysis of the 4PLs community based on an empirical study on all logistic service providers operating in France. Our methodology consists in the triangulation of information obtained from three studies (based on data contained in the DIANE database, and on data extracted from selected businesses websites).The results we found for the French 4PL community are also representative of the global 4PL, because our methodology is based on three studies which are therefore representative, reproducible and transferable to other countries. We propose a taxonomy and a new definition that differs from the traditional definition of Accenture.
\end{abstract}

Keywords Logistic, Organization, LSP, 4PL, Taxonomy

\section{Introduction}

Since the 1990s, the process of economic globalization has greatly contributed to the growth in the flow of goods by air, sea and land transport. In the last few years, the outsourcing of logistic functions to various types of 'logistics services providers' (LSPs) has become central to the organization of companies and markets [1,2]. In this context both theorists and practitioners usually present LSPs in terms of classifications or levels, describing their evolution with the help of representative statistics.

The highest and most complex level, 'fourth party logistics' (4PL), is a form of outsourcing that is essential to the organization of the global logistics chain [3-7]. Being considered a 4PL is the recognition of an undeniable expertise and reputation that makes the difference in comparison with all other types of LSPs.

Pure 4PL is described in the literature on the basis of the famous definition proposed in 1996 by Arthur Andersen (now Accenture Consulting), which originally registered the name as a trademark: "the 4PL is an integrator that assembles its own resources, capabilities and technology and those of other service providers to design and manage complex supply chains" [8]. The definition proposed by Accenture, which has been widely circulated, provides us with a first measure of the importance for a company to be considered a 4PL rather than simply a 'lead logistics provider' (LLP) or 'third party logistics' (3PL). Looking at this definition, we can begin to understand the heart of the problem. It is impossible to identify a precise population of firms that can be characterized as 4PL. Regardless, some authors have provided dollar estimates for the size of 4PL expenditures for their market. For example, according to Frost and Sullivan [9] "the 4PL market as a whole is expected to witness considerable revenue growth from approximately EUR 4.7 billion in 2002 to about EUR 13 billion by 2010". However one may reasonably wonder about the credibility of the statistics, since 4PL is not clearly defined.

Considering that $4 \mathrm{PL}$ is the next generation tendency of supply chain outsourcing, existing research focuses on its role in the supply chain [10], its operational advantages $[11,4,12]$, its dominant factors [13], its design [14], and on the optimization decision model of 4PL $[3,15,16,12]$. However all these works each analyze only one particular aspect of 4PLs, implicitly assuming that 4PLs are a homogeneous set of companies whose activities can be clearly distinguished from 3PLs and LLPs.

Although these works certainly contribute to the theoretical corpus on the development and role of 4PLs, they are inadequate in clearly identifying 4PLs. That explains why certain companies are sometimes considered as 3PL, LLP and sometimes as 4PL, depending on the theoretical or professional points of reference used and on local country practices. On this subject, according to Langley et al [17], in consideration of the differences between 3PL and 4PL, "there is a general dissatisfaction and confusion with the terminology".

Thus the question to answer is how to precisely 
characterize the 4PL community.

From a theoretical perspective, we propose a methodology to identify the 4PL community, a taxonomy of this group of companies, and a precise definition of their activities. This objective follows the recommendation of McCarthy [18] that states: "the ability to develop a well-defined theoretical or empirical classification is a basic step in conducting any form of scientific or systematic inquiry into the phenomena under investigation". From a practical point of view, the identification of the 4PL community can help companies collaborate with a 4PL.

This article is organized in four main sections. The first section describes the emergence of 4PLs through the main existing classifications with their inherent limitations. The second section presents our methodology, which consists of a global empirical study on all logistic service providers operating in France in order to identify the 4PL community. In the third section, we propose a taxonomy of 4PLs and a new definition based on distinct criteria. The fourth section discusses the results and examines how and why the studies conducted here can be applied to the majority of other countries. The conclusion presents the legitimacy for a LSP to be recognized as a $4 \mathrm{PL}$.

\section{Literature Review on LSP Classifications, Inherent Limitations and Questions}

The idea of classifying logistics services providers into some kind of hierarchy has attracted a great deal of attention. Classifying LSPs involves explaining how they are related to one another according to different criteria. Several complementary perspectives are considered in the literature, but they all display limitations due to a lack of formalism in dealing with either the different classes or the relations between those classes.

Belonging to a particular class has become an important economic and corporate issue to LSPs and their clients. Certain classes point to a high substitutability in the market and are therefore indicative of strong competition, leaving the LSP little room for competitive advantage. Other classes point to creators of value-add for their clients. Those LSPs derive their market power from the advantage obtained by taking into account the whole supply chain and business model of the client. Because their expertise is inimitable, their position is non-substitutable.

Table 1 below helps identify the scientific and institutional studies that highlight the LSP classifications and emphasize the existence of the 4PL (see table 1). The review period extends from 1996, the first year Accenture proposed a first definition of a 4PL, to today. Our choices exclude many articles published in professional magazines [19-24] in order to focus on the ones that are based on a more rigorous and accurate research methodology. It should be noted that the works published on 4PL are significantly less than for 3PL and that there is still no consensus on the definition of 4PL. The works are presented in chronological order and on the basis of the criteria used by their authors, i.e. whether derived from theoretical studies or from observations.

The classifications presented in Table 1 analyze the LSPs using different approaches. They address their role in the supply chain $[17,28,1]$, the complexity of their services [29-31] their impact on the performance of logistics services $[27,31]$, and the nature of services rendered as non-asset-based consulting or asset-based solution $[25,26]$.

These classifications have additional considerations. For example, Paché [29] points out that "the dematerialized LSP (that is to say, 4PL) have virtually no physical assets of their own". He is in agreement on this point with the classifications of Razzaque and Sheng [25] and Berglund et al [26]. According to Razzaque and Sheng [25] :"the asset-based providers could either be capacity-dedicated or assets-dedicated... The provider commits to meeting certain volume and service levels specified by the buyer, but will use its assets to serve multiple customers... In contrast, the non-asset-based providers generally do not own or lease physical assets but provide human resources and systems to manage the buyer's logistics function". And for Paché [29] : "the dematerialized LSP offer a bespoke solution to their clients by mobilizing their business network and by ensuring their coherence through total control of the information flows".

All these classifications commonly consider 4PL as the most complex form of LSP. In short, the most sophisticated classifications are those of Pigeon and Sirois [30] and Hsiao et al. [31] to which an intermediary level should be added: the 'lead logistic providers' (LLP) proposed by Selviaridi and Spring [28]. Thus, we adopt the following distinctions: LLP are 3PL that also carry out missions of the 4PL type. In other words, using their own assets, they propose a complete, integrated solution by carrying out logistic management activities on behalf of their clients. LLPs are therefore companies of a certain critical size, which diversify with the aim of satisfying demand of a complex, multi-business and international nature.

Hsiao et al. [31] propose a classification over four levels based on a theoretical study where the last level concerns the 4PL. Level 4 (total outsourcing) "refers to outsourcing the distribution network management". "LSPs take care of the logistics network management and orchestrate the logistics flow of the network from day to day". For Mukhopadhyay and Setaputra [4] 4PLs are therefore logical alternatives for the outsourcing of processes, providing higher visibility and integration through their networks. Risks are transferred to the 4PL, which are more committed through their autonomy and their responsibility in terms of quality assurance [7]. Jharkharia and Shankar [32] emphasize that the capability of a 4PL is to provide expertise and experience that would be difficult for clients to acquire in any other way, and too costly to maintain in-house. 4PLs do not have their own physical assets. They choose their subcontractors, they are 
legally accountable, and they have an obligation to produce results. In this, they are rather like freight forwarders whose role has been extended to include logistical engineering and computer services.

Table 1. Literature review: the existing classifications

\begin{tabular}{|c|c|c|}
\hline $\begin{array}{c}\text { Criteria of classification } \\
\text { of LSPs }\end{array}$ & Sources & Description of classes \\
\hline $\begin{array}{l}\text { Asset-based and non-asset } \\
\text { based }\end{array}$ & Razzaque and Sheng [25] & $\begin{array}{l}\text { - Asset-based providers own physical assets and focus on the } \\
\text { management and execution of transport and warehouse-related } \\
\text { activities. } \\
\text { - Non-asset based firms rely on human expertise and information } \\
\text { systems and offer management-oriented services. }\end{array}$ \\
\hline $\begin{array}{l}\text { Service or solution } \\
\text { providers }\end{array}$ & Berglund et al. [26] & $\begin{array}{l}\text { - LSP “service" (offering low cost, specific competitive services to } \\
\text { many clients) } \\
\text { - LSP "solution" (customized and complex services to a few key } \\
\text { clients) providers. }\end{array}$ \\
\hline $\begin{array}{l}\text { Service capabilities and } \\
\text { performance results (based } \\
\text { on RBV theory) }\end{array}$ & Lai [27] & $\begin{array}{c}-\mathrm{TFF}=\text { traditional freight forwarders } \\
-\mathrm{TMR}=\text { transformers } \\
-\mathrm{FSP}=\text { full service providers } \\
-\mathrm{NCR}=\text { Nichers }\end{array}$ \\
\hline Relationship structure & Langley et al. [17] & $\begin{array}{l}5 \text { types of companies are organized into two relationship structure : } \\
\text { Tactical structure (3PL and LSP) and strategic structure (4PL, LLP } \\
\text { and supply chain management) }\end{array}$ \\
\hline $\begin{array}{l}\text { Three levels: the firm, the } \\
\text { dyad and the network. }\end{array}$ & $\begin{array}{l}\text { Selviaridi and Spring } \\
\text { [28] }\end{array}$ & $\begin{array}{l}\text { - 3PL (third party logistics) } \\
\text { - LLP (lead logistic providers) } \\
\text { - 4PL (fourth party logistics) }\end{array}$ \\
\hline $\begin{array}{l}\text { Complexity of the supply } \\
\text { and level of outsourcing }\end{array}$ & Paché [29] & $\begin{array}{c}\text { - classic LSP (simple execution of transport-related physical } \\
\text { operations) } \\
\text { - value-added LSP (classic LSP + management of operations of an } \\
\text { industrial, commercial, administrative or informational nature) } \\
\text { - dematerialized LSP (which own almost no physical assets and can be } \\
\text { called 4PL) }\end{array}$ \\
\hline $\begin{array}{l}\text { Roles of LSP based on an } \\
\text { empirical European survey }\end{array}$ & Fabbes-Costes et al. [1] & $\begin{array}{c}\text { - facilitator LSP (which contribute to the chain integration or want to) } \\
\text { - integrated LSP (which are integrated into the client's chain or want } \\
\text { to be) } \\
\text { - operational integrator LSP (which integrate solutions for all or part } \\
\text { of the chain) }\end{array}$ \\
\hline $\begin{array}{l}\text { In terms of the services } \\
\text { provided }\end{array}$ & Pigeon and Sirois [30] & $\begin{array}{c}\text { - transport services (road, rail, sea, air) } \\
\text { - transport support services (maintenance, handling, navigation, } \\
\text { circulation, and intermediaries in freight transport, e.g. forwarding } \\
\text { agents and customs brokers) } \\
\text { - warehousing and storage services and third-party logistics service } \\
\text { providers (3PL) (all types of storage, labeling, offloading, stock } \\
\text { control and management, organization, order input and execution, } \\
\text { packing of orders, collection and packaging, marking and } \\
\text { organization of transport), } \\
\text { - courier and messenger services } \\
\text { - logistics consultancy services and external contractors with no } \\
\text { physical assets (4PL) }\end{array}$ \\
\hline $\begin{array}{l}\text { Distinction between } \\
\text { execution and planning \& } \\
\text { control activities in } \\
\text { operations management }\end{array}$ & Hsiao et al. [31] & $\begin{array}{c}\text { Planning level: this category comprises activities related to } \\
\text { formulating goals, developing strategies and outlining tasks and } \\
\text { schedules to accomplish the goals } \\
\text { - Level 4: distribution network management (total outsourcing) } \\
\text { - Level 3: inventory management or transportation management } \\
\text { Executive level: this category comprises activities related to } \\
\text { performing tasks } \\
\text { - Level 2: mixing flavors, packaging or labeling } \\
\text { - Level 1: transportation or warehousing }\end{array}$ \\
\hline
\end{tabular}


As for Pigeon and Sirois [30], they propose a classification derived from empirical observation of the logistics industry that was the subject of a report for the Quebec Ministry (Canada). They distinguish five categories based on the provided services: transportation services, transportation support services, storage services and 3PL, messaging services and messengers, and finally the logistics consulting services and outside service providers without assets (4PL). This last category is interesting, in the distinction they propose: "the logistics consulting services include custom consultants, consulting services for managing inventory control and planning, consultants for physical distribution, transport tariff auditors". The 4PLs therefore do not possess any kind of physical assets such as lorries or warehouses. Instead, they offer a bespoke and comprehensive solution for their client firms by mobilizing resources from different partners and ensuring their coherence while maintaining total control over the flow of information.

Although there is no doubt that the classifications are a reflection of the development of logistics activities, as expressed by business practices, how can we accurately identify the 4PLs? The question is important because there are uncertainties over the answer.

The first uncertainty relates to the theoretical classifications of LSPs into families or levels. The descriptions of the different families of service providers are not detailed enough. If the identification of companies performing services of type 1PL, 2PL and 3PL is easy, the same cannot be said of those providing services of type LLP and $4 \mathrm{PL}$. The descriptions remain relatively general because they are intended to encompass all the service providers in the world, only noting the points they have in common. In addition, up until now, the literature on the evolution of the different LSPs has only provided a partial view of their situation, firstly because the LSPs activities are present at many levels within the enterprise as demonstrated by the work of the 4PLs and secondly because there isn't, in general, a specifically defined 'logistics sector' in the economics classifications.

Can we then turn to the institutional economic nomenclatures, such as Classification of French Activities (NAF Rev2) or the North American Industry Classification System (NAICS - 2007) to get more details on the business of LSPs and to link nomenclatures and LSP classifications and thus identify the community of the 4PLs?

The second uncertainty relates to the classifications proposed in journals and magazines. The professional literature only contains lists of the 'Top 100 Global Logistics Providers' or the TOP 100,50 or 25 3PLs. But there is no such list for the 4PLs. There is an absence of any consensus in the professional classifications of companies, some of which are considered 3PL by some authors, and LLP or 4PL by others, because of confusion in the naming and structure of companies. For example, currently, no distinction is made between a group and its subsidiaries. A group like Kuhne\&Nagel, for example, has numerous subsidiaries throughout the world, but they are not all 4PL, LLP or 3PL. It all depends on which particular subsidiary one looks at. Another issue is caused by the scale of the market in logistics integration. It can accommodate not only 3PL companies having evolved to 4PL, but also management consulting firms and software and computing services companies specialized in supply chain management. Only the classification developed by Pigeon and Sirois [30] in Quebec (Canada) comes closer to providing a satisfactory solution to identify the type of LSP. However, this more rigorous study still encounters some limitations. The authors indicate the equivalence with the North American Industry Classification System (NAICS) for each family of activities except unfortunately for the 4PL. Therefore the transport services sector corresponds to the aggregate of the codes 481,482 , 483 and 484, the transport support services sector corresponds to code 488 , the courier and messenger services sector corresponds to code 492 and the sector of warehousing and 3PL corresponds to code 493. However, there is no clear distinction between warehousing and storage activities (code 493), and 3PL. This sector represents roughly 2000 companies in Canada, mostly with less than fifty employees. For their last category of firms - "logistics consultancy services and external contractors with no physical assets (4PL)" - Pigeon and Sirois [30] make a distinction between logistics consultancy services comprising customs consultants, inventory management consultants, physical distribution consultants, transport tariff checkers and 4PL firms, which "coordinate all the logistics activities entrusted to subcontractors". They list 12 firms in the 4PL category in Quebec (Canada).

The classification of firms within an industrial sector depends on the nature of their main activity. Certain firms may therefore be active in more than one sector, so it is impossible to statistically separate logistics consultants from other specialists in consulting. This means that the statistics for the logistics consultants are included in the NAICS micro-profile designated "Consulting Services Industry." Moreover, the jobs and firms that can be attributed to the Consulting Services Industry sector are not counted in the total number of jobs and firms in the logistics industry.

The study of this occupational classification leads us to the following question: can we examine the balance sheets of each company in order to identify the specific characteristics of 4PLs?

\section{Methodology}

Our study covers the whole population of French logistics services providers, 735 companies, listed in the online DIANE database. The survey was conducted on May 6, 2010. The site is accessible at http://www.bvdinfo.com/Products/ Company-Information/National/Diane.aspx. This database is a financial decision-making tool containing the financial statements and general information of companies who file their data with the Registries of the Commercial Courts (information relating to the economic activity, ownership, 
investments, administrators, legal form, etc...). Our starting point is the total population of companies $(1,200,000$ companies) on the French market whose description is that of service providers (174,900 companies) and whose activity within this category is that of logistics (735 companies).

Our goal is to study the logistics service providers in general and try to isolate in particular the 4PL ones. Our methodology consists in the triangulation of information obtained from three studies (see figure 1). The first and second studies were based on data contained in the DIANE database, and the third on data extracted from the websites of selected businesses.

The objective of information triangulation is to increase the strength of the analysis in this exploratory approach. It is not a simple procedure of cross-checking. It is a form of cross observation in order to explore all the possible ways for defining 4PLs.

First study - A quantitative survey of the codes in industry classification systems. The aim of the study is to identify the primary and secondary activities of LSPs using the following classifications: NAF Rév2 in France (NACE in Europe). An activity classification provides an understanding of how a country classifies its industrial activities. An industrial activity starts with an initial input (raw materials, half-finished products) and, by applying a particular technique, provides a given output (product). To begin with, the firms' activities are listed at their most detailed level. They are then evaluated, and the primary activities are grouped together according under the appropriate industrial classification. This study allows us to relate the different levels of LSP to activities codes in order to answer the following question: are there any industrial activity codes that can identify the 4PLs? We are seeking a relationship between the activity codes and the more advanced classifications for LSP defined by Hsiao et al. (2010) and Sirois and Pigeon (2010). Matches will be made through a link between the industrial classifications and the logistics trades.

Second study - An analysis of the corporate account profiles with the aim of identifying the main characteristics specific to the 4PL community. Are there any accounting criteria that would identify the 4PLs? To answer this question, we began searching for the accounting criteria that can best highlight the main characteristics that would unambiguously distinguish the 4PL from any other LSP. From the literature, two essential elements were identified: few or no physical assets and a strong consulting business.

The first set of accounting indicators we have chosen to examine are :

- raw materials which should have a low amount;

- change in stocks which should have a low amount;

- sales of goods produced which should have a low amount;

- gross fixed assets which should have a low amount;

- sales of services (turnover for services provided) should have a high number in the case of 4PL.
Industrial approach

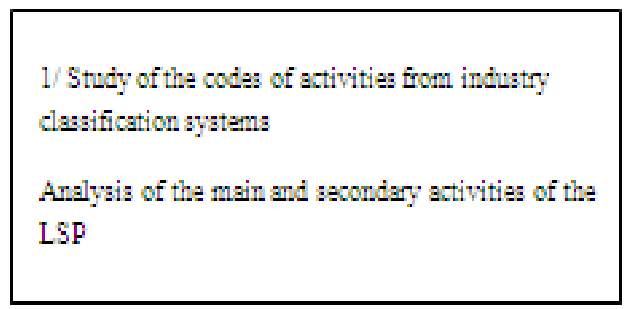

Are there one or more activity codes that can identify 4 PLs?
Accounting approach

2/ Study of the financial account profilea

Analysis of two ats of criteria identifying

companies with little or no physical assats, and

doing consulting work

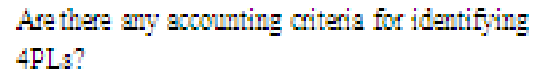

Are there any accounting criteria for identifying 4PLs?

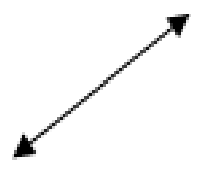

Analytical approach

3/ Websites study

Detailed analysis of the professional activities of LSP

Figure 1. Methodology 
These indicators must be considered together. The first set of indicators shows that these firms have few or no physical assets. Because they sell "grey matter", 4PL need human resources rather than physical means of production. The above characteristics have therefore been considered given the information present in the income statement (income statement show how the company's profit or loss is constituted) and balance sheet on the assets side (the balance sheet is a summary of the financial position of the firm at a given moment in time). Firstly, the presence of minimal physical assets is illustrated by indicators underlining the unimportance of production tools. In this case, the value (in thousands of euros) of these indicators tends towards zero.

The second set of accounting indicators we have chosen to examine are:

- turnover for services which should have a high amount;

- added value (in other words the difference between purchases and turnover) should have a high amount. This means that these firms purchase little, and their predominant factor of production is labor. Thus, the value-added rate (value-added to turnover ratio) should be higher than $60 \%$; - ratio of turnover to total wage bill which should have a value between [0 and 2] and lastly;

- ratio of turnover to workforce which should be close to $€ 100 \mathrm{~K}$ per employee.

The second set of indicators demonstrates the high level of consulting activity. All these indicators and rules of interpretation have been developed in collaboration with PricewaterhouseCoopers (Nice, France).
Third study. A qualitative study consisting of a detailed survey of company websites. The aim is to complete the first two studies determining, through the descriptions of the companies' activities, their market, their products and services and their customers. His will allow to identify which firms can be considered as 4PLs. Thus we can bring to light the characteristics they have in common and the ones that distinguish them.

In summary, Industry Classification Systems (first study) can account for homogeneous categories of companies on supply side, because firms are grouped according to their similarities when they produce the same product or service in terms of technology and production process. It suggests an interesting approach of "provision of services" in the field of "logistics". Activities recognized by this classification can partially characterize the LSPs. In the first part, we found that 4PL cannot be fully captured by the industry classification systems as their specific services are also based on the diversity and variability of the demand side. Thus, we need to gather additional criteria to identify the 4PLs. We preferred (second study) an analysis of accounting and financial information contained in the annual reports of companies. The key indicators we have selected from the corporate financial data present interesting tools to capture the 4PLs. At last, a detailed study of the companies' websites (third study) accounts for the markets in which they operate and the way they take into account their customers' needs from the demand side.

Table 2. Analysis of industrial codes in relation to classifications

\begin{tabular}{|c|c|c|c|}
\hline $\begin{array}{c}\text { Codes } \\
\text { Naf rév } 2\end{array}$ & Activities & $\begin{array}{l}\text { Correspondence with Hsiao's } \\
\text { classification }\end{array}$ & $\begin{array}{l}\text { Correspondence with Pigeon and Sirois' } \\
\text { classification }\end{array}$ \\
\hline 49 & $\begin{array}{l}\text { Transporter (without contract) (4941A, 4941B, } \\
4941 \mathrm{C})\end{array}$ & Level 1 & Transport services \\
\hline \multirow{5}{*}{52} & Warehousing and storage (5210A, 5210B) & Level 1 & $\begin{array}{l}\text { Warehousing services and third party } \\
\text { logistics (3PL) }\end{array}$ \\
\hline & Handling (5224A, 5224B) & Level 2 & Transport support services \\
\hline & Courier and Express Delivery (5229A) & Level 2 & Courier and messenger services \\
\hline & Charterer (5229B) & Level 3, LLP & Transport support services \\
\hline & Customs and transport brokerage (5229B) & Level 3, LLP, Level 4 & Transport support services \\
\hline \multirow{2}{*}{62} & Computer interfacing (6210Z) & Level 4 & E-logistics \\
\hline & Computer systems consulting (6202A & Level 4 & Logistics consulting services and 4PL \\
\hline \multirow{2}{*}{70} & $\begin{array}{c}\text { Management consulting: } \\
\text { without production activity (7010Z) }\end{array}$ & Intra-group activity & Intra-group activity \\
\hline & $\begin{array}{c}\text { Management consulting: } \\
\text { with production activity }(7022 \mathrm{Z})\end{array}$ & LLP, Level 4 & Logistics consulting services and 4PL \\
\hline 71 & Technical engineering (7112B) & Level 4 & Transport support services \\
\hline 77 & Transporter (with contract) $(7712 Z, 7739 \mathrm{Z})$ & Level 1 & Transport services \\
\hline \multirow{2}{*}{82} & Packager (8292Z) & Level 2 & $\begin{array}{c}\text { Warehousing services and third party } \\
\text { logistics (3PL) } \\
\end{array}$ \\
\hline & Codifier (8299Z) & Level 3, LLP & $\begin{array}{c}\text { Warehousing services and third party } \\
\text { logistics (3PL) }\end{array}$ \\
\hline \multicolumn{4}{|l|}{ NOTES } \\
\hline \multicolumn{4}{|c|}{$\begin{array}{l}\text { Charterers are intermediaries between clients who have goods to be shipped and transporters. They undertake to find the best conditions (cost, tim } \\
\text { and route) for their clients. }\end{array}$} \\
\hline \multicolumn{4}{|c|}{$\begin{array}{l}\text { E-logistics is the management of information and the tracking of orders and deliveries, in other words the integration of information and logistics } \\
\text { services. He brings together the offers of several transporters and allows the seller to choose from a range of logistics services. }\end{array}$} \\
\hline
\end{tabular}




\section{Results : Taxonomy of 4PLs and New Definition}

The 735 companies studied are classified according to their primary activity using a top-down methodology. This method for grouping logistics service providers point out that they are organize under 30 different codes. To begin with, firms' activities are listed at the most detailed level. They are then evaluated, and the primary activities are grouped together according to the industrial classification. The detailed description of the main groups and sub-groups shed a first light on LSPs' activities. This allows us to identify clear equivalences with the first levels of the classifications of Hsiao et al. [32] and Pigeon and Sirois [31], thanks to the link we have created between the nomenclature and the activities of logistics. By proposing one or more of the activities listed in the professional nomenclature for each sub-group definition (e.g., transport services -> transporter) we point up the correspondences (see table 2).Thus, we note that some codes have a clear correspondence with the first levels of the classification in Hsaio et al [32] and Sirois and Pigeon [31]. For example, code 49 corresponds to the transport activity and, unambiguously, to the first level of classification in Hsaio et al [32] and Sirois and Pigeon [31]. But this is no longer the case, once the activities of LSPs become more complex. For example code 52 includes activities that belong to more than one level of classifications. From another point of view, the literature defines the primary activity of a 3PL as a logistician. However, this activity does not correspond to a specific code. Indeed, a logistician is a provider of logistical services that operates on several levels. He has a role in the optimization of flow, transport, handling, inventory management, order picking, storage, packaging, shipping....and more. He uses physical and informational flows. His activities complement the functions of transportation and storage. Therefore, in the case of 4PL, there is not one specific industry code that can be used to isolate their community but at least five codes (see table 2).

To refine this study, we undertook the analysis of the companies' secondary activities that allow them to describe more accurately their main activity. A secondary activity is any activity of company's unit that results in the production of goods or services suitable for delivery to third parties. The analysis of secondary activities was conducted by analyzing the number of occurrences of certain keywords. We can see that out of the 735 companies, 41 have an activity out of context. There remain 694 companies, some of which have activities related to logistics but are classified in far-removed sections of industrial classifications systems.

To continue our investigations into the development of criteria identifying the community of 4PLs, we approached the problem from a different angle. We analyze the accounting profiles of the companies in order to expose two important specificities of 4PLs : a consulting business and a lack of physical assets. Indeed, given the heterogeneity of LSPs and the absence of economic and corporate facts that might allow us to isolate the LLP and 4PL, we have decided to search for empirical regularities in corporate information constructed in accordance with the reality of business. We have chosen a mechanism to generate new criteria (shown in the methodology - study 2) in order to improve our identification of 4PLs. This methodology is what underlies the analysis of the profiles of corporate accounts. We found 469 companies that satisfied the criteria of possessing few or no physical assets, 51 that met the criteria of a strong consulting activity and 46 that satisfied both criteria at the same time. To ensure the consistency of these results, we under took a third complementary study. It consisted of analyzing the daily activities of all businesses by examining their websites in detail. This study led us to eliminate some of the businesses since it turned out that they had physical assets (for example, transport activities in their own right). However, this study also uncovered some 4PL companies we had initially rejected. This was due to the fact that the results from either of the two sets of criteria used to identify 4PL companies were at the limit of what we considered to be acceptable values.

This lead us to retain 19 companies that could be considered as 4PL and that also met the above criteria (see table 3). Ultimately, from this table, three main categories emerged that distinguish the 4PL community in the industrial classifications: technical engineering; management or information system consulting and customs and transport brokerage. Out of these 19 companies, 4 are also regularly cited as being 4PL firms by the practitioners.

- Finally, the detailed analysis of the websites of these 19 4PL companies allowed us to better understand their daily activities. We initially found three distinct categories that prompted us to divide them into four groups (the customs and transport brokerage category is divided into two groups to bring more precision to the taxonomy) (see table 4):

Table 3. The 4PL

\begin{tabular}{|c|c|c|}
\hline $\mathrm{Nb}$ & Activities (NAF codes) & Companies names \\
\hline 1 & Warehousing and storage (5210B) & AdExcel, \\
\hline 6 & Customs and transport brokerage (5229B) & Clasquin, I.T.S Fabry, Gols, IPS Europe, 4 Pole, Alis international \\
\hline 3 & Computer system consulting (6202A) & $\begin{array}{c}\text { Segula conseil industriel, Transept informatique, Atos origin } \\
\text { international }\end{array}$ \\
\hline 1 & Managing consulting without production activities (7010Z) & Geodis solution \\
\hline 2 & Managing consulting with production activity (7022Z) & Crosslog, Eurobios \\
\hline 5 & Technical engineering (7112B) & Sonovision, Studec, LGM, Ekis France, A SIS \\
\hline 5 & Codifier (8299Z) & Logilec \\
\hline
\end{tabular}


Table 4. Taxonomy of 4PLs

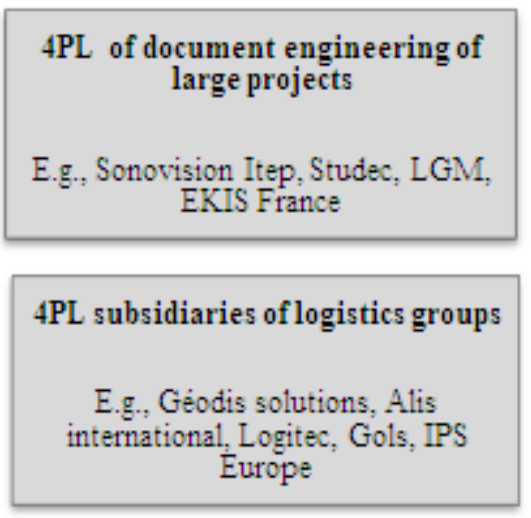

- a group of 4PLs consisting of document engineering of large projects which includes many of the 4PL active in technical engineering;

- a group of 4PLs consisting of logistics simulation by a modeling of logistics solutions. This includes part of the 4PL with a computer system consulting activity, a group of a business expertise and logistics consulting which we have subdivided by two in order to be more accurate;

- a group of 4PLs subsidiaries of logistics groups. These 4PLs reflect the development by large logistics groups of a subsidiary specifically dedicated to 4PL activities;

- and finally a group of pure 4PLs players who rely on other 4PL firms with activities in warehousing, storage, customs and transport brokerage.

Let us describe four groups briefly before moving on to propose a discussion and a definition of 4PL encompassing their common characteristics.

\section{Group 1 : 4PL of document engineering for large projects}

These 4PLs are specialized in document engineering for large projects. They propose the same services as non-specialized 4PLs, but with the difference that the services they provide concern information, data and documents rather than physical goods. The document engineering of large projects is therefore the design and management of technical information in the informational chain of large projects (aeronautical, naval, defense, military...). These logistics services comprise the following elements:

- writing and translation of documents (descriptive and functional manuals, product specifications, civilian and military standards, NATO codification, quality documents, documentation plan, specifications, etc.);

- storage and management of flows: archiving, digitization and circulation of data and documents to all the partners in the project, summary documents, etc.;

- information systems: development of systems of document production and consultation, management and circulation of technical libraries, knowledge capitalization software, etc;

- study of integrated logistics support: analysis of logistics

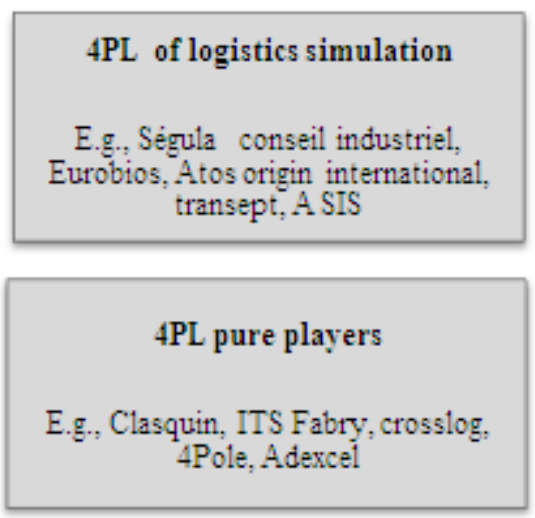

support (global process management), profitability analysis (study of project timetables and costs, performance indicators), assistance in selecting and supervising subcontractors and suppliers, technical assistance and maintenance, assistance in contracting and project management;

- accompaniment: training and staff assigned to clients (delocalized), etc.

\section{Group 2 : 4PL of logistics simulation}

These firms, independent subsidiaries of big consulting or software publishing groups, are devoted entirely to consulting and to the simulation of global logistics solutions. This allows them to develop integrated logistics management programs which they supply through specific software. Their activities consist in:

- modeling of supply chain elements (suppliers, factories, warehouses, distribution networks and clients) and their global integration into a project, the optimization of flows (of supply, production, stocks, and functioning of transport service providers), the optimization of the capacities and rules of warehousing and operational logistics operations and the modeling of performance (variations in demand and forecasts, etc.);

- transformation of computer infrastructures and trade operations, improvement of information flows throughout the supply chain, improving the planning and organization of the logistics chain in general, using a global and integrated information system and logistics databases;

- outsourcing that takes place mainly through the software that the 4PL develop and run and sometimes through missions of facilities management bringing added value to the client's information system.

\section{Group 3 : 4PL subsidiaries of logistics groups}

These are firms that are legally independent but created by a logistics group that also has LLP and 3PL type subsidiaries operating in Europe or through the world. They offer logistics consulting and organization to various clients in diverse sectors. They may operate either independently of the group, acting impartially by respecting an ethical charter that does not force them to deal with other subsidiaries of the 
group when proposing transport solutions for their clients or in close relation with other subsidiaries of the group that provide 3PL services or transport and customs brokerage operations. The most common activities are:

- global, collaborative and flexible solutions for the supply chain (management of the logistics project, operational assistance and principal contracting in logistics information systems, assignment of dedicated staff, etc.);

- network of partners to provide clients with the benefit of good coordination of outsourced transport flows;

- visibility and quality (management of outsourced logistic administrative processes, customs engineering (software packages for customs clearance, international taxation) and procedures dedicated to industrialists, tracking of ISO standard service provision, etc.);

- continuous improvement of budget control (administration of sales, reporting and dashboards, KPI).

Special case: 4PL subsidiaries dedicated exclusively to the group. This is the case of $4 \mathrm{PL}$ operating as the hub of a network of central purchasing departments and shops belonging to a group and with transactional platforms. It uses high-performance (secure and available) decision-making information systems to optimize the supply chain (flows of transport and data): consolidation of data and orders transmitted by members of the network; collection of goods from the suppliers, bulking on the platforms and organization of transport flows and coordination of information flows with external service providers.

\section{Group 4 : 4PL "pure players"}

These are independent companies of large or more modest size, representing a heterogeneous population. We have identified nine activities that can be used as criteria to define this category of 4PL. Companies can possess between six and nine of those criteria. Those satisfying all nine criteria can be considered as perfect pure players and can serve as reference points. These $4 \mathrm{PL}$ are positioned on a continuum ranging from 4PL "perfect pure players" as defined in the theoretical approaches through to 4PL "very imperfect pure players". Thus, the 4PL "perfect pure players" possess the maximum number of criteria compared to the other 4PL of this group. These 4PLs are characterized by the following essential features:

- an activity of expertise and consulting. They are pure service companies, possessing no physical assets related to the activity. These are all owned by the transporters: ships, planes, trucks and storage facilities. They use intellectual and computer resources to define and optimize the logistics chain, to manage and synchronize all the flows (upstream and downstream);

- an activity as integrator, expressed in the deployment of their own staff to clients for a specified period to best accompany them;

- an activity of transport brokerage for the flow of goods: mastery of local and international regulations, insurance law, selection of sub-contractors and other service providers, etc; - transfer of liabilities. They assume responsibility, in their own name or in the name of their clients, for all the contracts with service providers, suppliers and partners;

- the creation of their own international network to meet their clients' needs with several subsidiaries or local offices to strengthen the idea of proximity;

- a customs brokerage activity: management of customs formalities (drafting of customs declarations, information of nomenclatures, establishment of rate bases for duties and taxes, physical control of goods);

- specialization by segment, which can be based on international routes (e.g., Europe-Asia), one or more modes of transport (sea, air, road), certain sectors and several clients;

- a strong capability of real-time tracking and traceability of goods based on specific information systems;

- complex computer solutions dedicated to logistics. To conduct their activities in an integrated way, they use a combination of their own capacities and outside know-how.

There are very few "pure perfect players" 4PL. These are independent consulting firms whose role is to "design, organize and coordinate the whole of the logistics, documentary and regulatory chain to enable the client to send their goods from the point of departure to their destination" (Clasquin Website). These companies are "real architects of transport networks proposing turnkey global solutions, but also principal contractors managing the logistics solutions proposed to clients" (Clasquin website).

Around these "perfect" pure players orbit several "imperfect" 4PLs that only partially meet the criteria. For example, some firms satisfy the nine criteria but possess their own warehouses (ITS Fabry). Other 4PLs have a predominant activity of logistics consulting, combined with operations at the level of logistics solutions (handling, order processing, storage, etc.) and with warehouses (AdExcel, 4pole, Crosslog). The criteria most often absent concern the creation of the firm's own international network, customs brokerage and the transfer of liabilities.

Looking at the services offered by the heterogeneous category of 4PL "pure players", we believe that they are seeking to distinguish themselves from their competitors by emphasizing certain criteria in order to obtain an immediate competitive advantage. This is due to the fact that it is difficult for a company to compete optimally across multiple industries while providing all the services. This difficulty can be explained by several factors: highly-qualified personnel, long-term contracts with their clients ( 7 years on average), and high value-added in the provision of services that cannot be internalized.

Finally, on the basis of the taxonomy of 4PL presented above, common features emerge that allow us to establish a more pragmatic definition of $4 \mathrm{PL}$.

$4 P L$ are independent consulting firms whose role is to design, organize and coordinate the whole logistics, documentary and regulatory chain to enable a client to send goods, documents and information. They are integrators (principal contractor and project manager) that combine their own resources, capacities and technologies with those of other service providers to 
design and manage complex value chains based on the provision of dedicated computer services. They propose specific, turnkey global solutions, either directly or through computer modeling and facilities management. These solutions involve activities of transport and customs brokerage, civil and military codification, logistic engineering (storage, flow management), process management (administrative, quality, budget, performance, security and traceability processes), selection and supervision of sub-contractors and suppliers, etc. They possess few or no physical assets of their own, and are legally liable for the actions they manage in their own name or in the name of their clients over long periods. They respect the principles of sustainable development and charters of social responsibility and they have an obligation to produce results. They propose sector-based specialization over a zone that is extensive but not world-wide. In this respect, these firms are veritable network architects (they possess, either on their own or through partnerships, an international network in order to provide their clients with good coordination of flows abroad).

This definition is more precise than those proposed in the literature, but above all it corresponds to the corporate, economic and accounting reality. It evokes the long-term nature of contracts with clients, highly-qualified, specialized and reliable (low turnover) human resources, a strong corporate culture based on autonomy and local integration, a strong network within the group, a policy of alliances, centralization of decision-making, and open communication with the clients.

\section{Discussion}

With this study we have succeeded in moving from a simple specification of 4PLs to a more precise integration of these firms into the classification of LSPs. It was necessary to perform a complete categorization of all types of contexts observed within the framework of the studied phenomena, because existing LSP classifications adopt conceptual rather than empirical approaches. The taxonomy we have proposed deepens the last level in the various existing classifications (4PL or Level 4). If the first 3 levels were clearly identifiable, there was a blurring between 4PL and LLP. The originality of our methodological approach, allowed us to cover the entire range of 4PLs. "The 4PL concept is in a relatively nascent stage of development, ambiguity surrounding its definition has hindered quick consumer acceptance and support" [9]. Better understanding of French 4PLs can therefore allows the understanding of the existing distinctions between the U.S. and Europe as highlighted by O'Reilly [33]: "there are fundamental distinctions between U.S. and European perspectives..." Firstly, "in Europe, a 4PL is typically defined as a manager of other service providers. Transportation management, for example, is often considered a 4PL activity.... In the United States, we view transportation management as a $3 \mathrm{PL}$ engagement that is less strategic and more tactical" [33]. Secondly, the author stresses that we find more 4PLs in Europe compared to the United States as "the complexity of cross-border logistics in Europe is the perfect microcosms for a global 4PL model" [33]. And thirdly, "operating in multiple countries and managing a supply chain that needs to be much more global is a complicated proposition often not found in the United States. The 4PL concept is more acceptable in Europe because supply chains have to deal with inter-country trading" [33]. Our results may also help change the customer perception and remove ambiguities.

The analysis, the results of these three studies, completes the existing work on 4PL. One question remains regarding the contribution of this study and future works that might follow. Can it be argued that the results we found for the French 4PL community are also representative of the global 4PL?

Several factors contribute to the answer. The 735 LSPs represent the total population of LSPs for one country: France. By comparison, according to the study of Pigeon et al [30], Canada would count 2000 LSPs. In the work of Hsiao et al [31], the Netherlands had 385 LSPs and Taiwan 505 LSPs. Therefore the number of French LSPs relative to the size of France is consistent with other countries' practices. As Fulconis et al. [34] observed, "the provision of logistics services has become increasingly important in Western economies, in Europe, North America and South-East Asia, but also more recently in North Africa. For historical reasons, France is one of the most dynamic countries in this domain, along with the United Kingdom". Companies included in the taxonomy also own companies with subsidiaries abroad, indicating that the same type of activities exists and that the competitive configuration we have studied is similar to the one existing in other countries.

These three studies are therefore representative, reproducible and transferable to other countries. The first study addresses these scientific criteria because all countries have a classification of economic activities. They are in fact close to the ones we have used and corresponding tables exist to facilitate international comparisons. None of the tables offer codes reserved for the 4PL activities. For example, in the Canadian classification, the code that describes some of the 4PL activities is No. 541619, "Other Management Consulting services", but its content remains vague. This category comprises establishments primarily engaged in providing others with advice and assistance on matters of management. The following activities fall within this category: Consultants Customs, consultation for improving manufacturing operations, efficiency experts, logistics, auditor, transport tariff. All countries face the same difficulties in their codifications. Therefore, these results make sense globally, as they provide the beginning of a solution. More generally they raise an unresolved issue concerning the evolution of logistics skills and their full recognition in the nomenclatures of economic activities. This 
observation is consistent with the evolution of logistics skills in employment areas in which the service providers are active. Indeed, the logistics services are one of the factors in the attractiveness of the territories and contribute significantly to the overall balance of trade.

The second study meets the scientific criteria because the data included is available in the accounting profile of companies and thus is easily accessible. Indeed, Bureau VanDijk (company information and business intelligence), the creator of the Diane database, has also created similar databases covering Europe and the World. If we opted for an approach focused on a geographic area, it is to ensure the relevance and consistency of the studies. We were able to verify our results thanks to the analytical study. We have also made adjustments, highlighting the limitations of the accounting indicators we selected. In view of the results, it seems important to introduce other indicators (accessible through the database), to ensure greater reliability in a future study. For example, in Europe we proposed the profit margin of operations. The strategic positioning of $4 \mathrm{PL}$ in the value chain of their customers in terms of project leader, consultant and integrator of solutions, constitutes a real barrier to entry. Few companies are able to position themselves at the heart of their clients operations, by assuming responsibility for one or more logistics activities. This position is underpinned by the high technologies deployed. They prioritize innovation in information systems, in place of cost, as a mean of differentiation vis-à-vis the competition. These elements allow these companies to benefit from a high profit margin on their activities, which can be measured for example by the return on capital employed in activities in relation to turnover. The return on capital employed is particularly high when a company sells mostly know-how and takes over the existing assets of its customers transforming them into service centers [35]. To promise their customers increase productivity gains compared to existing practices, the 4PLs require a more intensive use of information technology, a pooling of resources and skilled human capital with significant intellectual capacity. By having a critical mass, they can acquire these skills and are then able to increase their advocating power with regards to their clients in order to win longer term contracts. They also have a bargaining power with respect to their stronger partners that they can use to achieve price reductions that a client on its own cannot negotiate.

The third study meets the scientific criteria because data are public. The websites of 4PLs are a reflection of their daily practices and offers they can provide.

\section{Conclusion}

The advantage for an LSP to be identified as 4PL is the recognition of an expertise and a reputation based on three key concepts: neutrality, the assurance of a comprehensive offer and a strong potential for human capital at the service of the clients. Neutrality for a 4PL means to be legally and organizationally independent of a logistics group. It is therefore free to offer independent solutions and establish external partnerships [35]. It is not required to deploy first the forces and products in its group. Especially that the dependence of the customer is all the greater when the process it is seeking is critical to its business [6]. The 4PL offers its customers a comprehensive offer [9,5]. It seeks and evaluates, on behalf of its clients, the providers (1PL, 2PL, 3PL) that will be incorporated in the network based on their experience and skills $[37,36,5]$. It can focus on finding the providers who can contribute most cost-effectively to the improvement of the company's logistics. The LSP is a unique contributor ("4PLs act as an interface and a single point of contact between the parties" [36] who shares the risks with the clients and offers multi-services, multi-techniques and multi-supports [38]. "4PLs make sure more agile response is achieved even in complex networks. As a pipeline integrator, 4PLs make use of their expertise and knowledge of managing global supply chain" [376 It thus creates value by being at the heart of a network of relationships [9,5,7]. The 4PL are "Human Capital Intensive Firms" that rest on inalienable and inimitable critical resources (knowledge, skills, expertise, talents ...) that an individual can control and enhance in its special relationship with his company [39-41]. According to Gavrielatos [42], "the human capital of a services firm (e.g. a 4PL Service Provider) equals the knowledge and skills of its professionals that can be used to produce consulting (e.g. logistics consulting).and to contribute to the enactment of strategies that improve performance (e.g. the logistics network performance)". The 4PL are full of creativity in the sense that they are in constant search of new organizational concepts and techniques in order to find new opportunities for their clients. These three notions are a token of recognition for companies that outsource their logistics activities. They also legitimize this particular type of LSP.

\section{Acknowledgements}

I would like to thank the reviewers for their constructive comments. I would like to thank Guy Usseglio of PricewaterhouseCoopers, Nice, France for his help in producing the accounting ratios used in the empirical analysis and Vick Beyrouti, Technology Services Consulting Group- Encino CA- US, for proof reading the document and for his many comments.

\section{REFERENCES}

[1] N. Fabbe-Costes., M. Jahre, C. Roussat. Supply chain integration: the role of logistics service providers, International Journal of Productivity and Performance Management, Vol.58, No.1, 71- 91, 2008.

[2] C.Wong, N.Karia. Explaining the competitive advantage of 
logistics service providers: A resource-based view approach, International Journal of Production Economics, No.128, 51-67, 2010.

[3] X. Li, W. Ying, W. Liu, J. Chen, B. Huang. The decision optimization model of 4PL, Systems, Man and Cybernetics. IEEE International Conference, Vol.2, No.5-8, 1241-1245, 2003.

[4] S. Mukhopadhyay, R. Setaputra. The role of 4PL as the reverse logistics integrator: Optimal pricing and return policies, International Journal of Physical Distribution \& Logistics Management, Vol.36, No.9, 716-729, 2006.

[5] A. Win. The value a 4PL provider can contribute to an organization. International Journal of Physical Distribution \& Logistics Management, Vol.38, No.9, 674-684, 2008.

[6] F. Krakovics, J. Lea, P. Mendes, R. Santos. Defining and calibrating performance indicators of a 4PL in the chemical industry in Brazil, International Journal of Production Economics, No.115, 502-514, 2008.

[7] G. Buyukozkan, O. Feyzioglu, M. Ersoy. Evaluation of 4PL operating models: A decision making approach based on 2 -additive Choquet integral, International Journal of Production Economics, No.121, 112-120, 2009.

[8] D. Bade, J. Mueller. New for Millennium, 4PL, Transportation and Distribution, February, 78-80, 1999.

[9] Frost and Sullivan. Fourth-Party Logistics: Turning A Cost Into A Value Proposition, Supply Chain Management, No.1-2, 2004.

[10] J. Bumstead, K. Cannons. From 4PL to managed supply-chain operations, Logistics \& Transport Focus, Vol.4, No.4, 18-24, 2002.

[11] H. Lau,. Y. Goh. An intelligent brokering system to support multi-agent Web-based 4th-party logistics, In Proceedings of the 14th IEEE international conference on tools with artificial intelligence, 154-161,2004.

[12] K.H Chen, C.T. Su. Activity assigning of fourth party logistics by particle swarm optimization-based preemptive fuzzy integer goal programming, Expert Systems with Applications, No.37, 3630-3637, 2010.

[13] C. Bourlakis, M. Bourlakis. Information technology safeguards, logistics asset specificity and fourth-party logistics network creation in the food retail chain, The Journal of Business \& Industrial Marketing, Vol.20 No.2, 88-99, 2005.

[14] W. Tan, F. Yang, R. Chen, X. Zhao. A system architecture to SOA-based 4PL using RDF, In: IEEE International Conference on Automation and Logistics, 866-870, 2007.

[15] L. Liu, J. Yao. Multi-objective optimization algorithm analysis on supply chain resources integration decision in 4PL, In IEEE International Conference on Automation and Logistics, 1852-1857, 2007.

[16] J. Yao. Decision optimization analysis on supply chain resource integration in fourth party logistics, Journal of Manufacturing Systems, No.29, 121-129, 2010.

[17] C. Langley, E. van Dort, A; Ang, S. Sykes. Third Party Logistics, Results and findings of the 10th annual study, $1-46,2005$.
[18] I. McCarthy. Manufacturing classification: lessons from organizational systematic ad biological taxonomy, Integrating manufacturing systems, Vol. 6, No.6, 37-48, 2005.

[19] S. Stone. Are 4PLs for real ?, Purchasing, January No.14, 103, 1999.

[20] W.Armbruster. 4PL, JoCWeek, June, 24-30, 2002.

[21] J. Love. 3PL/4PL - Where next?, Focus, April, 18-21, 2004.

[22] D. Warrilow. Become your own 4PL, Logistics \& Transport Focus, March, 37-40, 2007.

[23] R. F. Boughton. The great debate 3PL vs 4PL, Logistics \& Transport Focus, December, 24-28, 2007.

[24] S. Johnston. Reaping the benefits of fourth-party logistics, Focus, November, 2007.

[25] M.Razzaque, C. Sheng. Outsourcing of logistics functions: a literature survey, International Journal of Physical Distribution \& Logistics Management, Vol.28, No.2, 89-107, 1998.

[26] M. Berglund, P. Van Laarhoven, G. Sharman, S. Wandel. Third party logistics: is there a future?, International Journal of Logistics Management, Vol.10, No.1, 59-70, 1999.

[27] K. Lai, K.. Service capability and performance of logistics service providers, Transportation Research: Part E, Vol.40, No.5, 385-99, 2004.

[28] K. Selviaridis, M. Spring. Third party logistics: a literature review and research agenda. The International Journal of Logistics Management, Vol.18, No.1, 125-150, 2007.

[29] G. Paché. Les 4PL capitalisent-ils les savoirs issus du pilotage des chaînes logistiques étendues ? in P.L. Dubois and Y. Dupuy, Connaissance et Management, Economica, 2007.

[30] Online Available: http:// e.g.: Pigeon S., Sirois M., Industrie .de la logistique, Gouvernement du Québec. Online Available from http: //www.mdeie.gouv.qc.ca/fileadmin/contenu/publications/por traits_industriels/industrie_logistique.pdf, 2010.

[31] H. Hsiao, R. Kemp, J. van der Vost, S. Omta. A classification of logistic outsourcing levels and their impact on service performance: evidence from the food processing industry, International Journal of Production Economics, No.124, 75-86, 2010.

[32] S. Jharkharia, R. Shankar. Selection of logistics services provider: an analytic network process (ANP) approach, Omega International Journal of Management Science, No.35, 274-289, 2007.

[33] J. O'Reilly. 4PLs Take Control, Inbound logistics, January, 2011.

[34] F. Fulconis, G. Paché, G. Roveillo. La prestation logistique. Origines, enjeux et prespectives. Editions EMS Management et société, 2011.

[35] C. Hoarau. Externalisation des services à l'industrie : enjeux du développement des groupes multiservices, Rapport final pour le Ministère de l'économie, des finances et de l'industrie - DGE, 2007. 
[36] S. Kutlu. Fourth Party Logistics: Is It the Future of Supply Chain Outsourcing?, Brendwood UK, Best Global Publishing, 2007.

[37] J. Coyle, E. Bardi, C. Langley. The Management Of Business Logistics: A Supply Chain Perspective, 7th ed., South-Western Publishing, Mason, OH, 2003.

[38] D. Bowersox, D. Closs, M. Cooper. Supply Chain Logistics Management, 2nd ed., McGraw-Hill, New York, NY, 2007.

[39] R. Rajan, L. Zingales. Power in a Theory of the Firm, Quarterly Journal of Economics, Vol.113, No. 2, 387-432, 1998.
[40] R. Rajan, L. Zingales The Influence of the Financial Revolution on the Nature of Firms. American Economic Review, AEA Papers and Proceedings, Vol.91, No.2, 206-211, 2001.

[41] L. Zingales. In Search of New Foundations, Journal of Finance, Vol.55, No. 4, 1623-1653, 2000.

[42] A. Gavrielatos. The Role of the Logistics Service Providers in the Improvement of the Nordic Logistics Networks A Swedish Perspective, Logistics and Transport Management. Master Thesis. Goteborg University, 2007 